\title{
DEGRADATION OF BENZO [A] PYRENE BY A NOVEL STRAIN Bacillus subtilis BMT4i (MTCC 9447)
}

\author{
Madhuri Kaushish Lily ${ }^{1}$, Ashutosh Bahuguna ${ }^{1}$, Koushalya Dangwal ${ }^{1}$, Veena Garg ${ }^{2}$ \\ ${ }^{1}$ Department of Biotechnology, Modern Institute of Technology (MIT), Dhalwala, Rishikesh-249201, Uttarakhand, India; \\ ${ }^{2}$ Department of Bioscience and Biotechnology, Banasthali University, Rajasthan, India.
}

Submitted: October 01, 2008; Returned to authors for corrections: November 04, 2008; Approved: May 15, 2009.

\begin{abstract}
Benzo [a] Pyrene $(\mathrm{BaP})$ is a highly recalcitrant, polycyclic aromatic hydrocarbon $(\mathrm{PAH})$ with high genotoxicity and carcinogenicity. It is formed and released into the environment due to incomplete combustion of fossil fuel and various anthropogenic activities including cigarette smoke and automobile exhausts. The aim of present study is to isolate bacteria which can degrade $\mathrm{BaP}$ as a sole source of carbon and energy. We have isolated a novel strain BMT4i (MTCC 9447) of Bacillus subtilis from automobile contaminated soil using $\mathrm{BaP}(50 \mu \mathrm{g} / \mathrm{ml})$ as the sole source of carbon and energy in basal salt mineral (BSM) medium. The growth kinetics of BMT4i was studied using CFU method which revealed that BMT4 $\mathrm{i}$ is able to survive in BaP-BSM medium up to 40 days attaining its peak growth $\left(10^{29}\right.$ fold increase in cell number) on 7 days of incubation. The BaP degradation kinetics of BMT4i was studied using High Performance Liquid Chromatography (HPLC) analysis of BaP biodegradation products. BMT4i started degrading $\mathrm{BaP}$ after 24 hours and continued up to 28 days achieving maximum degradation of approximately $84.66 \%$. The above findings inferred that BMT4i is a very efficient degrader of BaP. To our best of knowledge, this is the first report showing utilization of $\mathrm{BaP}$ as a sole source of carbon and energy by bacteria. In addition, BMT4i can degrade a wide range of PAHs including naphthalene, anthracene, and dibenzothiophene therefore, it could serve as a better candidate for bioremediation of PAHs contaminated sites.
\end{abstract}

Key words: Benzo [a] Pyrene (BaP), polycyclic aromatic hydrocarbon (PAH), Bacillus subtilis BMT4i, colony forming units/ml (CFU/ml), high performance liquid chromatography (HPLC)

\section{INTRODUCTION}

High molecular weight (HMW) polycyclic aromatic hydrocarbons (PAHs) are considered environmentally significant because of their potential toxicity to the higher organisms and resistance to microbial attack (5). Usually, an increase in the number of fused rings increases the chemical stability and hydrophobicity of PAH molecules, making them more amenable to biodegradation. In mammals, PAHs are shown to possess high mutagenic, teratogenic or carcinogenic properties $(9,14,24)$ therefore, many PAHs including phenanthrene, acenaphthene, acenaphthylene, fluoranthene, pyrene, benzo[a] pyrene $(\mathrm{BaP})$ and benzo[a] anthracene are listed in the priority pollutant list of the United States Environmental Protection Agency $(20,26)$.

Benzo [a] Pyrene (BaP), a potent carcinogen is a 
pentacyclic high molecular weight $\mathrm{PAH}$ with high recalcitrant nature $(4,5,24,27)$. The natural sources of $\mathrm{BaP}$ are forest fires, volcanic eruptions, peat fires, burning of crude oil and shale oil, while anthropogenic sources include the incomplete combustion of fossil fuel, coke oven emissions, aluminum smelters, coal combustion and conversion industries, incinerators, vehicle exhausts, cigarette, cigar and marijuana smoke (2, 3). From contaminated soil and water, $\mathrm{BaP}$ enters into the food chain and metabolized to its ultimate genotoxic form which then interacts with nucleic acids and proteins forming highly reactive macromolecular adducts resulting in $\mathrm{BaP}$ induced toxicity, mutagenesis and carcinogenesis in mammals $(8,12$, $23)$. In contrast to the mammalian system, some algal, fungal and bacterial species are shown to degrade $\mathrm{BaP}$ cometabolically, alone or in a co-culture $(16,18,22)$. However, bacteria capable of utilizing $\mathrm{BaP}$ as a sole source of carbon and energy have never been demonstrated.

In view of the above, the present study is focused on the isolation and characterization of bacterial species capable of degrading $\mathrm{BaP}$ as the sole source of carbon and energy.

\section{MATERIALS AND METHODS}

\section{Chemicals and Reagents}

The benzo (a) pyrene (BaP) (99.9\%), benzo (a) pyrene cis- 7, 8 dihydrodiol, naphthalene, anthracene and dibenzothiophene (purity > 98\%) were purchased from Supelco, USA. Tryptone, peptone, beef extracts, bacto-agar, yeast extracts and staining reagents were obtained from HiMedia Laboratory Pvt. Ltd. India. The general chemicals including constituents of basal salt mineral media (BSM) and solvents of analytical grade were purchased from Glaxo Pvt. Ltd. India and Merck Pvt. Ltd. India.

\section{Preparation of Media}

BSM ( $\mathrm{pH}$ 7.0) was prepared by dissolving $0.38 \mathrm{~g}$ $\mathrm{KH}_{2} \mathrm{PO}_{4}, 0.6 \mathrm{~g} \mathrm{~K}_{2} \mathrm{HPO}_{4}, 0.2 \mathrm{~g} \mathrm{MgSO}_{4} .7 \mathrm{H}_{2} \mathrm{O}, 1.0 \mathrm{~g} \mathrm{NH} \mathrm{NH}_{4} \mathrm{Cl}$ $0.05 \mathrm{~g} \mathrm{FeCl}_{3}$ in one liter double distilled water and autoclaved. Autoclaved nutrient broth contained $5 \mathrm{~g}$ peptone, $5 \mathrm{~g} \mathrm{NaCl}, 3 \mathrm{~g}$ beef extracts, $3 \mathrm{~g}$ yeast extracts per liter double distilled water. All the solid media contained 1.5\% agar along with BSM or nutrient broth. The stock solution $(10 \mathrm{mg} / \mathrm{ml})$ of $\mathrm{BaP}$, benzo (a) pyrene cis- 7, 8 dihydrodiol, naphthalene, anthracene and dibenzothiophene were made in dimethylformamide and was sterilized by Millipore micro syringe filter assembly $(0.45 \mu \mathrm{m}$ pore size).

\section{Isolation of BaP degrading bacteria}

The subsurface PAH-contaminated soil sample was collected from automobile workshop situated in Srinagar Garhwal, Uttarakhand, India.

The automobile contaminated soil was suspended in BSM $(10 \% \mathrm{w} / \mathrm{v})$ with vigorous stirring for 10 minutes and then allowed to settle at room temperature for one hour. The supernatant was serially diluted up to $10^{-9} .100 \mu \mathrm{l}$ inoculum of $10^{-7}$ diluted soil suspension was spread on BSM- agar plate supplemented with $\mathrm{BaP}(50 \mu \mathrm{g} / \mathrm{ml})$ as sole source of carbon and energy and incubated for 1 week at $37^{\circ} \mathrm{C}$ inside the clear plastic bags to conserve moisture. The bigger size bacterial colonies which appeared on BSM-BaP plate were aseptically removed and reselected on $\mathrm{BSM}-\mathrm{BaP}$ plate to obtain their pure culture. Single colony of each isolate is then inoculated in $10 \mathrm{ml}$ nutrient broth and grown for $24 \mathrm{~h}$ at $37{ }^{\circ} \mathrm{C}$ with constant shaking at $150 \mathrm{rpm}$ (Remi, India, Model no. CIS24). The cell suspensions were centrifuged at $8000 \mathrm{rpm}$ for 10 minutes to obtain cell pellets of each soil isolate. The cell pellets were washed with BSM three times to remove the trace of nutrient broth and finally suspended in BSM. The optical densities of cell suspensions were adjusted to 1.0 approximately equal to the $10^{8}$ cells per $\mathrm{ml}$. The ability of each soil isolate to grow in the presence of $\mathrm{BaP}$ was checked by inoculating $1 \mathrm{ml}$ of each soil isolates (approx. 10 cells $/ \mathrm{ml}$ ) into the $10 \mathrm{ml}$ of BSM supplemented with BaP (50 $\mu \mathrm{g} / \mathrm{ml})$ as the sole source of carbon and energy. The cultures were incubated at $37^{\circ} \mathrm{C}$ for 1 week with constant shaking at $150 \mathrm{rpm}$ in dark to avoid photolysis of $\mathrm{BaP} .100 \mu \mathrm{l}$ each of grown culture were taken out and diluted serially upto $0-10^{-}$ 20. $100 \mu \mathrm{l}$ of each serially diluted culture were spread over BSMG plate (BSM containing glucose $10 \mathrm{gL}^{-1}$ ) and incubated 
for $12-24 \mathrm{~h}$ at $37^{\circ} \mathrm{C}$. The colonies were counted and $\mathrm{CFU} / \mathrm{ml}$ was determined for each culture. In addition, the cultures were virtually examined for the turbidity at $600 \mathrm{~nm}$ using UV-Vis Spectrophotometer (Systronics, India, model no. 119). The best BaP degrader (BMT4i) was selected on the basis of its highest growth in BaP-BSM as indicated by highest CFU/ml (Table 1) and turbidity at $\mathrm{A}_{600}$.

Table 1. Characteristics and Viability of soil bacterial isolates in BaP-BSM after 7 days

\begin{tabular}{lll}
\hline Soil isolate & Morphology & CFU/ml \\
\hline BMT128 & Rod shaped, gram + & $5 \times 10^{16}$ \\
BMT637(R) & Fusiform rod shaped, gram + & $4 \times 10^{19}$ \\
BMT4i & Rod shaped, gram + & $6 \times 10^{35}$ \\
BMT5i & Rod shaped, gram + & $3 \times 10^{23}$ \\
BMT628 & Fusiform rod shaped, gram + & $2 \times 10^{18}$ \\
DMT628 & coccus, gram + & $4 \times 10^{13}$ \\
BMT137 & Rod shaped, gram + & $4 \times 10^{16}$ \\
DMT137(R1) & Rod shaped, gram + & $3 \times 10^{20}$ \\
DMT137(R2) & Rod shaped, gram + & $5 \times 10^{20}$ \\
DMT128 & coccus, gram + & $6 \times 10^{14}$ \\
\hline
\end{tabular}

\section{Identification and characterization of the BaP degrading bacterium BMT4i}

The BMT4i was maintained on BaP supplemented BSM agar plates. The identification and characterization of the BMT4i was done on the basis of the cell and colony morphology, growth characteristics, motility, various staining reactions and various biochemical tests as given by Bergey's Manual of Systematic Bacteriology (6) as mentioned in the results (Table 2). For molecular characterization, BMT4i genomic DNA was isolated and approximately $1.5 \mathrm{~kb} 16 \mathrm{~S}$ rDNA gene fragment was amplified by PCR (Biometra, Germany, model Tpersonal) using the forward primers 5'ACCACATGCAAGTGCAACG-3' and reverse primer 5'ACGGGCGGTGTGTAC-3'. The amplified product was purified by agarose gel electrophoresis and clone into the
pGEM-T vector (Promega Scientific, Santa Barbara, California). Both the strands of cloned approximately $1.5 \mathrm{~kb}$ 16S rDNA gene fragment were sequenced using sequencing facility provided by Bangalore Genei, India. The approximately $1.5 \mathrm{~kb}$ region of the $16 \mathrm{~S}$ rDNA gene was used for alignment and phylogenetic analysis. The sequences were compared to those in GenBank by using the Blast Alignment Tool and the software based on "Neighbor Joining Method" was used to construct phylogenetic tree. The aligned sequences were deposited to the GenBank, EMBL and DDBJ libraries. The culture of BMT4i was deposited in Microbial Type Culture Collection (MTCC), Institute of Microbial Technology (IMTECH), Chandigarh, India.

\section{Assessment of degradation ability of BMT4i}

All the operations were carried out in dim yellow light in order to avoid photo degradation of BaP. All the experiments were set up in triplicates. A single colony of BMT4i maintained in BaP-BSM agar plate was inoculated in $10 \mathrm{ml}$ nutrient broth and grown at $37^{\circ} \mathrm{C}$ with constant stirring till the $\mathrm{A}_{600}$ reaches to 1.0 (approx. $1 \times 10^{8}$ cells $/ \mathrm{ml}$ ). The cell culture was centrifuged at $8000 \mathrm{rpm}$ for 10 minutes and washed three times with BSM to remove trace of nutrient broth. The BMT4i cell number was adjusted to $10^{8}$ cells $/ \mathrm{ml}$ in BSM. For the time course studies, $1 \mathrm{ml}$ of BMT4i- BSM suspension was re-inoculated in various flasks $\left(10^{7}\right.$ cells $\left./ \mathrm{ml}\right)$ containing $10 \mathrm{ml} \mathrm{BSM}$ supplemented with $50 \mu \mathrm{g} / \mathrm{ml}$ of BaP as the sole source of carbon and energy and incubated at $37^{\circ} \mathrm{C}$ in incubator shaker at $120 \mathrm{rpm}$ for various time periods along with their respective controls devoid of BMT 4i. At various time points ( $0,12 \mathrm{~h}, 1,2,3,7,14,21,28,35,42$ days), first of all, the $\mathrm{A}_{600}$ was recorded and then $\mathrm{CFU} / \mathrm{ml}$ of BMT4i was checked by removing $100 \mu \mathrm{l}$ culture from all the experimental and control flask, diluting up to $10^{-40}$ and plating over BSM-glucose agar plate. After $24 \mathrm{~h}$, the numbers of colonies were counted and the $\log _{10} \mathrm{CFU} / \mathrm{ml}$ was calculated to obtain the growth curve. The respective cultures were then extracted twice with ethyl acetate $(1: 1 \mathrm{v} / \mathrm{v})$, acidified to $\mathrm{pH}$ 4.0 with $0.1 \mathrm{~N} \mathrm{HCl}$ and re-extracted twice with ethyl acetate 
Table 2. Physical and biochemical characteristics of Bacillus subtilis BMT4i (MTCC 9447)

\section{Test}

Results

\author{
Morphological characterization \\ shape and arrangement \\ capsule \\ gram staining \\ spore staining \\ motility \\ acid fast staining
}

\author{
short, chains \\ positive \\ positive \\ positive, round shaped, terminal \\ motile \\ non acid-fast
}

\section{Culture characterization on agar plates}

colonies

temperature

growth

form

margins

elevation

density

\author{
white, abundant mucilage \\ optimum \\ abundant \\ irregular \\ serrate \\ flat \\ translucent
}

\section{Growth on broth}

surface growth

clouding

sediment

\section{Biochemical tests}

Oxidase

Catalase

Nitrate reduction

Litmus milk

Urease

$\mathrm{H}_{2} \mathrm{~S}$ production

Methyl red

Vogues proskaeur

Citrate utilization

Indole production

Carbohydrate fermentation
a. Lactose
b. Mannitol
c. Sucrose
d. Glucose
e. Maltose

Starch hydrolysis

Gelatin hydrolysis

Casein hydrolysis

Lipid hydrolysis

$$
\begin{aligned}
& \text { pellicle } \\
& \text { slight } \\
& \text { flaky }
\end{aligned}
$$

to enhance the recovery of acidic metabolites. The entire triplicate extracts of respective time period were separately dried in rotary evaporator (Perfit, Ambala, India, model no. 951) and finally suspended in $1.0 \mathrm{ml}$ of methanol. The recovery of biodegraded products by ethyl acetate extraction was found to be more than $96 \%$. The extent of $\mathrm{BaP}$ biodegradation was checked by quantifying left over BaP in methanol suspension of biodegraded extracts by HPLC analysis $(13,21)$. The reverse phase HPLC was done on commercial basis from Herbal Research and Development Institute (HRDI), Selaqui, Dehradun, India (HPLC system: Waters, USA, model no. 600 E pump with Photo Diode 
Array (PDA) detector). For that, $20 \mu \mathrm{l}$ of the methanol dissolved extracts were injected into an HPLC system fitted with $5 \mu \mathrm{m}$ particle diameter $\mathrm{C}_{18}$ column. The elution gradient was programmed as follows (shown as percent [by volume] of methanol in water, acidified with $0.76 \mathrm{ml}$ of $\mathrm{H}_{3} \mathrm{PO}_{4}$ liter $\left.{ }^{1}\right)$ : $50 \%$ for $2 \mathrm{~min}$, linear gradient to $80 \%$ at $5 \% \mathrm{~min}^{-1}$, holding at $80^{\circ} \mathrm{C}$ for $16 \mathrm{~min}$. The flow rate was kept at $1 \mathrm{ml}$ min- ${ }^{1}$. Peaks were measured at $254 \mathrm{~nm}$. The percent degradation of $\mathrm{BaP}$ was assessed by subtracting left over $\mathrm{BaP}$ in experiments (with BMT4i) from the respective controls (without BMT4i; recovered products were considered as $100 \%)$ at various time intervals $(0,12 \mathrm{~h}, 1,2,3,7,14,21,28$, 35, 42 days).

\section{Viability of BMT4i in the presence of other PAH}

To check the viability of BMT4i in the presence of other PAHs, the overnight grown nutrient broth culture of BMT4i was washed three times with BSM and spread over BSM plates containing $500 \mu \mathrm{g} / \mathrm{ml}$ each of naphthalene, anthracene and dibenzothiophene (DBT) as the sole sources of the carbon and energy. After $24-48 \mathrm{~h}$ of incubation at $37^{\circ} \mathrm{C}$, the plates were observed for appearance of colonies. The CFU/ml was determined by inoculating thoroughly washed BMT4i culture $\left(10^{7}\right.$ cells $\left./ \mathrm{ml}\right)$ in BSM broth containing naphthalene, anthracene and dibenzothiophene (DBT) $(500 \mu \mathrm{g} / \mathrm{ml})$ in separate flasks and CFU/ $\mathrm{ml}$ was calculated after 7 day of incubation at $37^{\circ} \mathrm{C}, 150 \mathrm{rpm}$.

\section{RESULTS}

\section{Isolation and identification of a BaP degrading bacterium}

The BaP degrading bacterial colonies were isolated from automobile contaminated soil by standard culture enrichment techniques with $\mathrm{BaP}$ as the sole source of carbon and energy. Among various BaP degrading bacterial isolates, the BMT4i was selected as best $\mathrm{BaP}$ degrader on the basis of its highest growth in BaP-BSM as indicated by highest $\mathrm{CFU} / \mathrm{ml}$ (Table1) and turbidity at $\mathrm{A}_{600}$ after 7 days of growth. BMT4i was further characterized on the basis of cell and colony morphology, various staining and biochemical activities (Table 2) and 16S rDNA gene analysis. The cellular and colony morphology, various staining reactions and biochemical reactions identified BMT4i as a Bacillus subtilis. Two of its unique biochemical characteristics viz-abundant mucilage secretion and urease positive reaction indicated BMT4i as a novel strain of Bacillus subtilis. The sequence and comparative phylogenetic analysis of PCR amplified 16S rDNA gene fragment of BMT4i to those in GenBank confirmed BMT4i as the closest homologue and a novel strain of Bacillus subtilis (NCBI GenBank Accession No. DQ911348, MTCC 9447) (Figure 1).

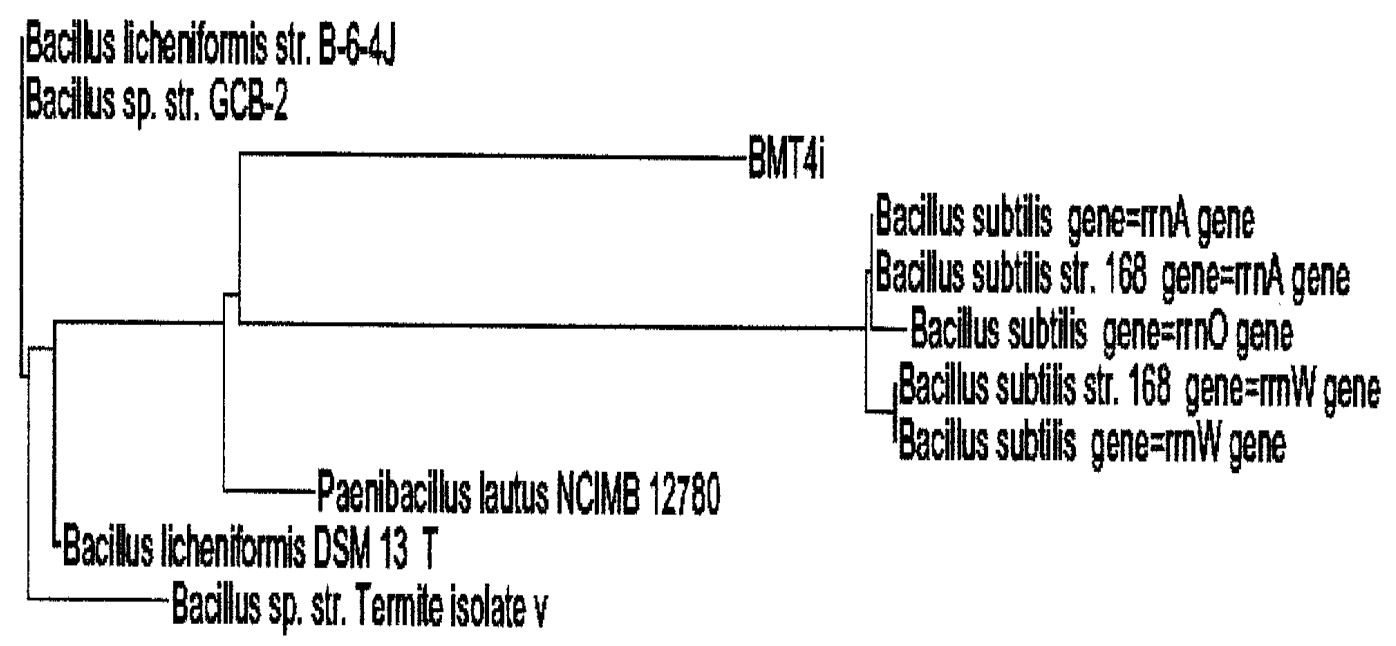

Figure 1. Phylogenetic analysis of Bacillus subtilis BMT4i based on 16S rDNA sequence analysis 


\section{Growth Kinetics of BMT4i in the presence of BaP}

The growth kinetics experiment revealed that the BMT4i possess ability to utilize $\mathrm{BaP}$ for its biomass production. As shown in the plot of $\log _{10}$ of $\mathrm{CFU} / \mathrm{ml}$ against incubation time, after $12 \mathrm{~h}$ of lag phase, $\log _{10} \mathrm{CFU} / \mathrm{ml}$ of BMT4i increases exponentially with increase in incubation duration up to $7^{\text {th }}$ day and there after it declines (Figure 2). At the beginning, $7.46 \log _{10} \mathrm{CFU} / \mathrm{ml}\left(\sim 2 \times 10^{7} \mathrm{CFU} / \mathrm{ml}\right)$ of BMT4i was added to the BaP-BSM medium, which almost remain constant (7.5 $\log _{10} \mathrm{CFU} / \mathrm{ml}$ ) for $12 \mathrm{~h}$, started increasing linearly after $24 \mathrm{~h}$
(8.4 $\log _{10} \mathrm{CFU} / \mathrm{ml}$ ) attaining maximum $36.77 \log _{10} \mathrm{CFU} / \mathrm{ml}$ $\left(6.0 \times 10^{36}\right)$ on $7^{\text {th }}$ day of incubation showing approx $4 \times 10^{29}$ fold increase in the cell number. The CFU/ml declined slowly after $7^{\text {th }}$ day reaching to zero on 42 day. About $4 \times 10^{29}$ fold increase in the CFU number is directly correlated with the ability of Bacillus subtilis BMT4i to utilize $\mathrm{BaP}$ as the sole source of carbon and energy which leads to high increase in cell number within just 7 days, which starts declining afterwards possibly due to the exhaustion of $\mathrm{BaP}$.

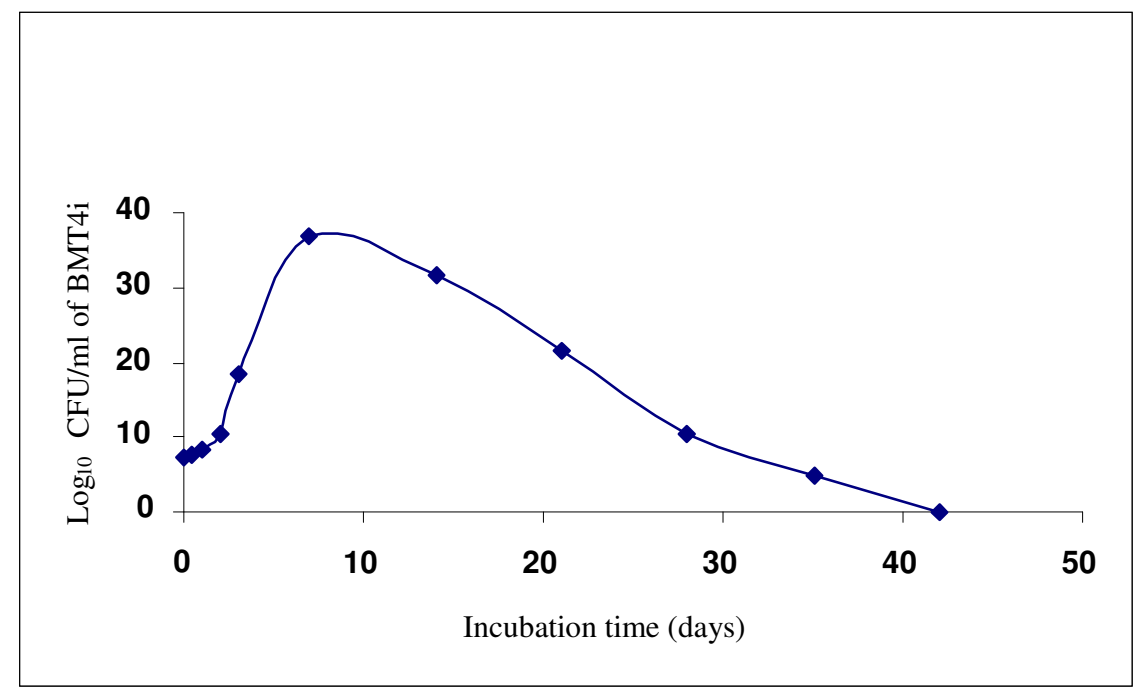

Figure 2. Counts $\left(\log _{10} \mathrm{CFU} / \mathrm{ml}\right)$ of Bacillus subtilis BMT4i (MTCC 9447) in BSM with BaP against incubation time (days). Each point represents the average value obtained with triplicate flasks.

\section{Assessment of BaP degradation}

The HPLC profile for $\mathrm{BaP}$ and its metabolites after 7 days of growth of BMT4i in BaP medium was compared with that of negative control (without BMT4i) (Figure $3 \mathrm{~A}$ and B ). The chromatogram showed six additional peaks (I, II, III, IV, V, VI) indicating different metabolites formed during the degradation of $\mathrm{BaP}$. The analysis of metabolites is under study. The plot of percent BaP degradation against incubation time (Figure 4), demonstrated that Bacillus subtilis BMT4i possess ability to degrade $\mathrm{BaP}$ as shown by the linear increase in $\mathrm{BaP}$ degradation with time. BMT4i started degrading $\mathrm{BaP}$ after $24 \mathrm{~h}$ and continued up to day 28 . On 12 $\mathrm{h}$, no detectable amount of degradation was seen suggesting it as lag phase of degradation. On day 1, BMT4i mediated BaP degradation efficiency was about $5.18 \%$ that increased exponentially up to 7 day (about $48.34 \%$ ), and there after with slow increase it became static on day $28(84.66 \%)$. Further incubation of 35 days and 42 days doesn't show any further increase in $\mathrm{BaP}$ degradation. Whereas, on day 2, 3, 14 and 21, BMT4i was able to degrade about 12.28\%, 21.77\%, $60.12 \%$ and $73.92 \% \mathrm{BaP}$ respectively. Although, the number of viable cells $\left(\log _{10} \mathrm{CFU} / \mathrm{ml}\right)$ decreased considerably after 7 day of growth in $\mathrm{BaP}$ medium, the BMT4i continued to degrade $\mathrm{BaP}$ up to 28 days. 
Lily, M.K. et al.

(A)

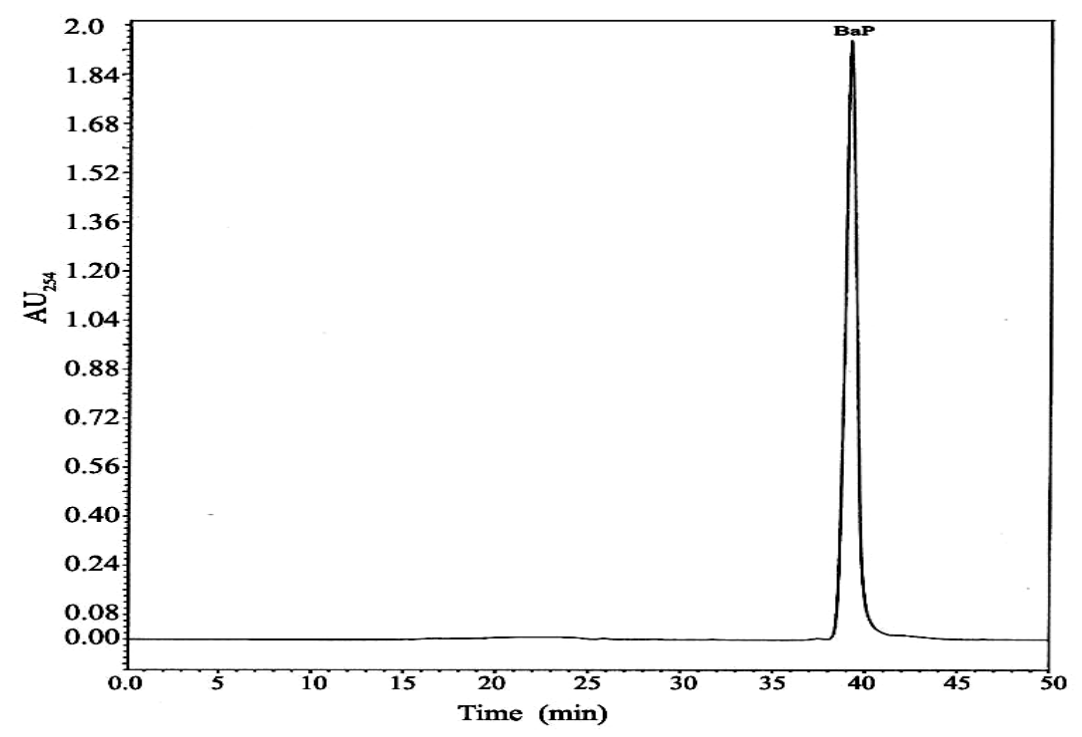

(B)

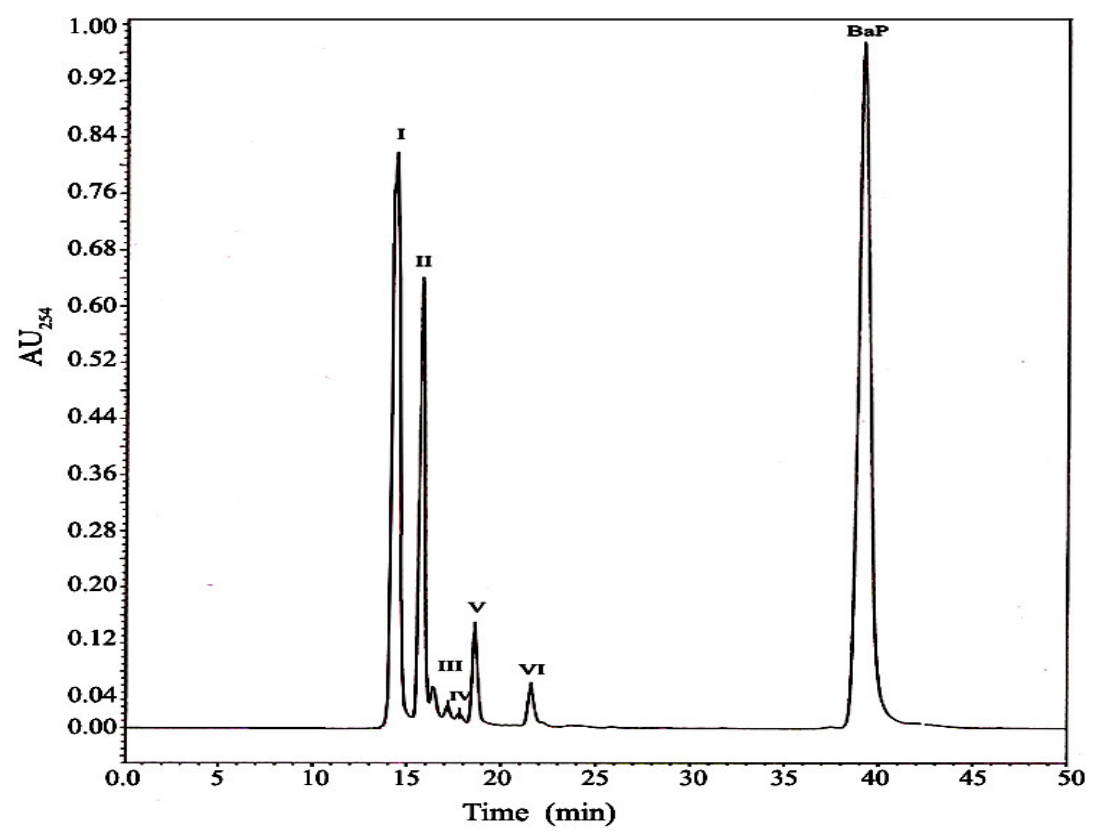

Figure 3. The HPLC profile for BaP and its metabolites after 7 days of incubation: (A) Without BMT4i (negative control); (B) with BMT4i in BSM- BaP medium

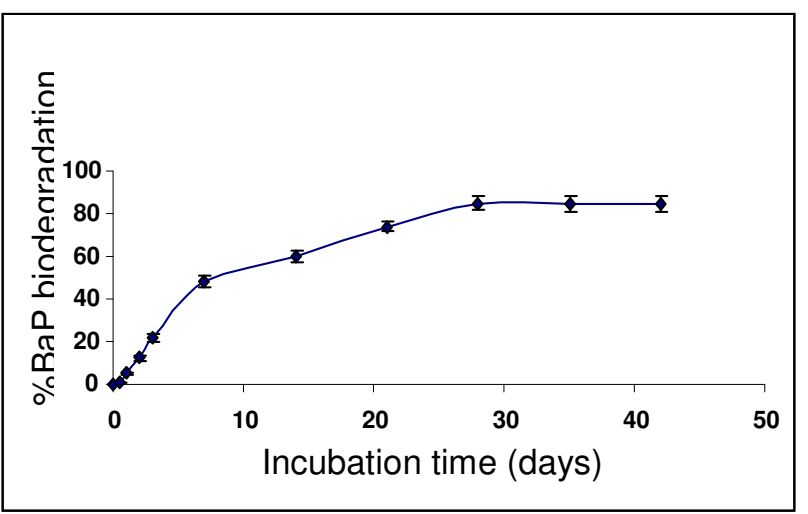

Figure 4. Percentage (\%) degradation of $\mathrm{BaP}(50 \mu \mathrm{g} / \mathrm{ml})$ by Bacillus subtilis BMT4i (MTCC 9447) with respect to time (days). Each point represents the average value obtained with triplicate flasks. The error bars represent the standard deviations of triplicate independent experiments. 


\section{Viability of BMT4i in the presence of other PAH}

Bacillus subtilis BMT4i possess the ability to utilize naphthalene, anthracene and DBT as the sole source of carbon and energy as indicated by the appearance of numerous colonies after $48 \mathrm{~h}$ of growth over the respective PAH containing plates. This was further confirmed by $\mathrm{CFU} / \mathrm{ml}$ after 7 days of growth in respective PAH containing broth. The CFU/ml was found to be about $10^{52}$ (naphthalene), $10^{49}$ (anthracene) and $10^{56}$ (DBT).

\section{DISCUSSION}

Present study is the first report demonstrating the utilization of $\mathrm{BaP}$ as a sole source of carbon and energy by bacteria. The novel strain Bacillus subtilis BMT4i (MTCC 9447) showed $10^{29}$ fold enhancement in biomass with in 7 days and about $84.66 \%$ of BaP degradation after 28 days of growth. The HPLC profile of 7 days incubation showed six additional peaks indicating intermediate metabolites. The identification of metabolites is under study. At present it is not clear whether the decrease in $\mathrm{CFU} / \mathrm{ml}$ after 7 days is due to the accumulation of toxic metabolites or exhaustion of $\mathrm{BaP}$ as carbon and energy source. Our study is different from other studies in following three aspects. First, all the reported $\mathrm{BaP}$ degradation by bacteria have been shown to occur cometabolically i.e., in the presence of additional carbon sources. Second, none of the bacterial species showed viability for such a long duration (40 days) in BaP-BSM medium. Third, this much of high BaP degradation efficiency has not been reported by earlier studies. Early observation of $\mathrm{BaP}$ biodegradation was made with mutant Beijerinckia sp. strain B8/36 and Pseudomonas sp. strain NCIB 9816 grown on succinate plus biphenyl and succinate plus salicylate (1,

7). Mycobacterium vanbaalenii PYR-1 using peptone, yeast extracts, and soluble starch as the additional carbon sources was able to degrade $24.7 \%$ of $\mathrm{BaP}$ in pure culture where as in sediment water microcosm experiment it was able to mineralize $36 \%$ of added $\mathrm{BaP}$ after 28 days $(10,11)$. In another study, Mycobacterium sp. Strain RJGII-135 showed $25 \%$ co-metabolic mineralization of $\mathrm{BaP}$ in soil after 180 days (8). In a different study, Mycobacterium sp. strain RJGII-135 demonstrated about $40 \%$ degradation of BaP after 32 days (25). Co-metabolic degradation (41\%) of $\mathrm{BaP}$ was also demonstrated by Burkholderia cepacia strains after 56 days (15). Some of the other studies involved use of bacterial consortium derived from soil which co-metabolically mineralizes $\mathrm{BaP}$ to greater than $95 \%$ in 150 days and $33-65 \%$ with in two weeks when provided with a complex hydrocarbon co substrate such as crude oil and diesel fuel separately in soil $(17,19)$. In a recent study, Bacillus subtilistgr3 isolated from PAH contaminated soil was able to transform $55 \%$ and $65 \%$ of $\mathrm{BaP}$ with in $48 \mathrm{~h}$ and $72 \mathrm{~h}$ at $30^{\circ} \mathrm{C}$ when grown on minimal media supplemented with sodium citrate (13). However, during incubation, tgr-3 showed only $10^{2}$ fold enhancement in cell number after 48 hours after that it declined drastically becoming non-viable with in 96 hours.

Bacillus subtilis BMT4i also possess ability to degrade other PAHs such as naphthalene, anthracene and dibenzothiophene. Since Bacillus subtilis BMT4i has been isolated from automobile contaminated soil and is well adapted to PAHs including $\mathrm{BaP}$ contaminated environment, therefore it could serve as better model for bioremediation of PAH contaminated site and removal of PAHs including BaP from the environment.

\section{ACKNOWLEDGEMENTS}

This work was supported in part by the Modern Institute of Technology, Rishikesh, Uttarakhand, India and Uttrakhand Council of Science and Technology, Uttarakhand, India (UCOST; grant no. UCS and T/R and D/LS-46/06-07), thatare gratefully acknowledged. We also thank Prof Aditya Shastri, Vice Chancellor, Banasthali University, Rajasthan, India for providing facilities in the Dept. of Bioscience and Biotechnology at this university. 
Lily, M.K. et al.

\section{REFERENCES}

1. Barnsley, E.A. (1975). The bacterial degradation of fluoranthene and benzo [a] pyrene. Can. J. Microbiol. 21 (7), 1004-1008.

2. Blumer, M. (1976). Polycyclic aromatic hydrocarbons in nature. Sci. Am. 234 (3), 35-45.

3. California Environmental Protection Agency (1997). Public health goal for Benzo [a] Pyrene in drinking water. p. 1-42.

4. Cerniglia, C.E. (1992). Biodegradation of polycyclic aromatic hydrocarbons. Biodegradation 3, 351-368.

5. Cerniglia, C.E. (1993). Biodegradation of polycyclic aromatic hydrocarbons. Curr. Opin. Biotechnol. 4, 331-338.

6. Claus, D.; Berkeley, R.C.W. (1986). Genus Bacillus. Sneath, P.H.A.; Mair, N.S.; Sharpe, M.E.; Holt, J.G. (ed.) Bergey's Manual of Systematic Bacteriology, 1st ed., vol. 2, 1105-1139.

7. Gibson, D.T.; Mahadevan, V.; Jerina, D.M.; Yagi, H.; Yeh, H.J. (1975). Oxidation of the carcinogens Benzo [a] Pyrene and Benzo [a] anthracene to dihydrodiols by a bacterium. Science 189, 295-297.

8. Grosser, R.J.; Warshawsky, D.; Vestal, J.R. (1991). Indigenous and enhanced mineralization of pyrene, benzo[a] pyrene and carbazole in soils. Appl. Environ. Microbiol. 57: 3462-3469.

9. Harvey, R.A. (1996). Mechanisms of carcinogenesis of polycyclic aromatic hydrocarbons. Polycyclic Aromatic Compounds 9, 1-23.

10. Heitkamp, M.A.; Cerniglia, C.E. (1988). Mineralization of the polycyclic aromatic hydrocarbons by a bacterium isolated from sediment below an oil field. Appl. Environ. Microbiol. 54, 1612-1614.

11. Heitkamp, M.A.; Cerniglia, C.E. (1989). Polycyclic aromatic hydrocarbon degradation by a Mycobacterium sp. in microcosms containing sediment and water from a pristine ecosystem. Appl. Environ. Microbiol. 55, 1968-1973

12. Hsu, G.W.; Huang, X.; Luneva, N.P.; Geacintov, N.E.; Beese, L.S. (2005). Structure of a high fidelity DNA polymerase bound to a Benzo [a] pyrene adducts that blocks replication. J. Biol. Chem. 280 (50), 3764-3770.

13. Hunter, R.D.; Ekunwe, S.N.; Dodor, D.E.; Hwang, H.M.; Ekunwe, L. (2005). Bacillus subtilis is a potential degrader of pyrene and benzo [a] pyrene. Int. J. Environ. Res. Public Health 2 (2), 267-271.q

14. International Agency for Research on Cancer. (1990). Monographs on the evaluation of carcinogenic risks to humans. Vol 1, 1972-1979.

15. Juhasz, A.L.; Britz, M.L.; Stanley, G.A. (1997). Degradation of benzo[a]pyrene, dibenz[a,h]anthracene and coronene by Burkholderia cepacia. Water Science and Technology 36, 45-51.

16. Juhasz, A.L.; Naidu, R. (2000). Bioremediation of high molecular weight polycyclic aromatic hydrocarbons: a review of the microbial degradation of benzo[a]pyrene. Int. Biodeterior. Biodeg. 45, 57-88.

17. Kanaly, R.; Bartha, R.; Fogel, S.; Findlay, M. (1997). Biodegradation of $\left[{ }^{14} \mathrm{C}\right]$ benzo [a] pyrene added in crude oil to uncontaminated soil. Appl. Environ. Microbiol. 63, 4511-4515.

18. Kanaly, R.A.; Harayama, S. (2000). Biodegradation of high molecular weight polycyclic aromatic hydrocarbons by bacteria. J. Bacteriol. 182 (8), 2059-2067.

19. Kanaly, R.A.; Bartha, R.; Watanabe, K.; Harayama, S. (2000). Rapid mineralization of benzo [a] pyrene by a microbial consortium growing on diesel fuel. Appl. Environ. Microbiol. 66, 4205-4211.

20. Keith, L.H.; Telliard, W.A. (1979). Priority pollutants I- a perspective view. Environ. Sci. Technol. 13, 416-423.

21. Moody, J.D.; Freeman, J.P; Fu, P.P; Cerniglia, C.E. (2004). Degradation of Benzo [a] pyrene by Mycobacterium vanbaalenii PYR1. Appl. Environ. Microbiol. 340-345

22. Muncnerova, D.; Augustin, J. (1994). Fungal Metabolism and Detoxification of Polycyclic Aromatic Hydrocarbons: A Review. Biores. Technol. 48, 97-106.

23. Okona-Mensah, K.B.; Battershill, J.; Boobis, A.; Fielder, R. (2005). An approach to investigating the importance of high potency polycyclic aromatic hydrocarbons (PAHs) in the induction of lung cancer by air pollution. Food Chem. Toxicol. 43 (7), 1103-1116.

24. Phillips, D.H. (1983). Fifty years of benzo[a]pyrene. Nature 303, 468472.

25. Schneider, J.; Grosser, R.; Jayasimhulu, K.; Xue, W.; Warshawsky, D. (1996). Degradation of pyrene, Benzo[a] anthracene and Benzo[a]pyrene by Mycobacterium sp. strain RJG II -135, isolated from a former coal gasification site. Appl. Environ. Microbiol. 62, 13-19.

26. Smith, J.R.; Nakles, D.V.; Sherman, D.F.; Neuhauser, E.F.; Loehr, R.C. (1989). The Third International Conference on New Frontiers for Hazardous Waste Management. U.S. Washington, DC: Environmental fate mechanisms influencing biological biodegradation of coal tar derived polynuclear aromatic hydrocarbons in soil systems. Environmental Protection Agency, p. 397-405.

27. Sutherland, J.B.; Rafii, F.; Khan, A.A.; Cerniglia, C.E. (1995). Mechanisms of polycyclic aromatic hydrocarbon degradation. In L.Y. Young and C.E. Cerniglia (ed.), Microbial transformation and degradation of toxic organic chemicals. Wiley-Liss, New York, N.Y., p. 269-306. 